\title{
Fatality after hepatic angiography in Zieve's syndrome
}

\author{
S. PICKENS \\ M.B., Ch.B., M.R.C.P. \\ University Department of Therapeutics and Clinical Pharmacology, The Royal Infirmary, \\ Edinburgh EH3 9YW
}

\begin{abstract}
Summary
A patient with Zieve's syndrome is described. Following hepatic angiography, the patient became shocked and eventually died. The hazards of hepatic angiography are discussed and its use in ill patients questioned.
\end{abstract}

\section{Introduction}

The syndrome of jaundice, hyperlipaemia and haemolytic anaemia associated with alcoholic liver disease was first described by Zieve in 1958. A case of Zieve's syndrome is described in which, following hepatic angiography, the patient rapidly deteriorated and eventually died.

\section{Case report}

A 66-year-old female was referred to a haematological out-patient clinic with a 10 -month history of tiredness, breathlessness, anorexia and weight loss. Apart from occasional attacks of cystitis, her past medical history was uneventful and her family history unhelpful. She admitted to a generous regular alcohol intake, approximately half a bottle of whisky daily.

On examination, she was jaundiced, clinically anaemic and there were signs of recent weight loss. Jugular venous pressure was not elevated but there was mild ankle oedema. The pulse was $100 / \mathrm{min}$ and regular, BP 110/80 $\mathrm{mmHg}$ and cardiac auscultation was normal. The abdomen was distended and ascites was demonstrated. The liver was hard, non-tender and $4 \mathrm{~cm}$ enlarged. A systolic bruit was heard over the liver. The spleen was not palpable.

\section{Investigations}

Haemoglobin, $5 \cdot 7 \mathrm{~g} / \mathrm{dl}$; haematocrit $0 \cdot 200 ; \mathrm{MCV}$ $118 / 1$; MCHC, $28.5 \mathrm{~g} / \mathrm{dl}$; platelets, $140 \times 10^{9} / 1$; WBC, $30.1 \times 10^{9} / 1$; differential, neutrophils, $92 \%$; lymphocytes, $6 \%$; monocytes, $2 \%$; ESR $41 \mathrm{~mm}$ in the first hour; reticulocytes, $11 \cdot 5 \%$. In the peripheral blood film, the red blood cells were macrocytic, normochromic with moderate polychromasia. Prothrombin time $1.5: 1$. Serum $B_{12}, 479 \mathrm{ng} / 1$; serum folate, $2 \cdot 1 \mu \mathrm{g} / \mathrm{l}$. Coombs' test was negative.
Urea, $5 \cdot 2 \mathrm{mmol} / \mathrm{l} ; \mathrm{Na}, 134 \mathrm{mmol} / 1 ; \mathrm{K}, 3.3 \mathrm{mmol} / 1$; total $\mathrm{CO}_{2}, 24 \mathrm{mmol} / \mathrm{l}$. Serum bilirubin, $275 \mu \mathrm{mol} / \mathrm{l}$; alanine aminotransferase, $<10 \mathrm{u} . / \mathrm{l}$; alkaline phosphatase, $348 \mathrm{u}$./1. Total protein, $69 \mathrm{~g} / \mathrm{l}$; albumin, 33 $\mathrm{g} / \mathrm{l} ; \alpha$-fetoprotein negative. Serum cholesterol, $9 \cdot 3$ mmol/l; triglycerides, $1.9 \mathrm{mmol} / 1$. A technetium liver scan suggested either multiple small metastases or hepatic cirrhosis. Shortly after admission, the patient developed a low grade fever.

She was transfused with 6 units of packed cells and received vitamin $K$, neomycin, spironolactone, and a low sodium and protein diet. Four days after admission, the reticulocyte count had fallen to $2 \cdot 3 \%$ and it remained around this level. Hepatic angiography demonstrated an increased arterial supply to an enlarged liver and the appearances were in keeping with an early stage of cirrhosis. Unfortunately, following this procedure, her blood pressure fell to a systolic pressure of $80 \mathrm{mmHg}$ and the pulse rate increased to $120 / \mathrm{min}$. She received $300 \mathrm{ml}$ saltpoor albumin intravenously and because of the deepening jaundice, the possibility of septicaemia was considered. She was started on gentamicin and lincomycin intravenously and was transfused a further unit of packed cells. Her bilirubin during this period rose to $450 \mathrm{mmol} / 1$ and 5 days later there was a transient rise in the serum alanine aminotransferase to $75 \mathrm{u}$./1. Her serum sodium was persistently low and her blood urea had risen to $11 \mathrm{mmol} / \mathrm{l}$. Her electrolyte imbalance proved resistant to all measures tried to correct it and her condition gradually deteriorated until she died 7 weeks after admission.

At post-mortem, the peritoneal cavity contained 3.5 litres of clear bile-stained fluid. The liver weighed $1.3 \mathrm{~kg}$, had a finely nodular surface and was greenish in colour. On cut section, the parenchyma was deeply bile-stained and a micro-nodular pattern of cirrhosis was detectable. There was no evidence of hepatoma. Microscopic examination showed extensive fibrosis of the portal triads without evidence of regeneration, and extensive ante-mortem necrosis with polymorphonuclear infiltration. The surviving hepatocytes contained large amounts of Mallory's hyaline. The appearances were consistent with severe 
and prolonged liver damage due to alcohol, and not cirrhosis. No abnormalities were demonstrated in the biliary system or spleen.

\section{Discussion}

Selective hepatic angiography was first described by Bierman et al. in 1951. Since that time, it has been used in the diagnosis of a wide variety of liver diseases (Alfidi et al., 1968). The hazards of angiography include infection, embolization, thrombosis, extravasation of dye, toxic effects of the contrast medium and damage to other blood supplies to vital organs. In 1974, Goldstein and Bookstein monitored the liver function tests in 26 patients having hepatic angiography and they reported only 2 transient elevations of the serum transaminase levels. Ritchie (1975) using a canine model, suggested that contrast media, in the presence of induced endothelial damage, could produce more extensive damage and severe inflammatory changes, together with red cell aggregation and fibrin formation. He also noted the formation of thrombus.

Although the findings in the present patient were consistent with a diagnosis of Zieve's syndrome, the possibility of hepatoma or hepatic metastases had been raised. The technetium liver scan was unhelpful, as the changes in alcoholic hepatitis can resemble neoplastic deposits. Hepatic angiography was therefore carried out to exclude neoplasia before embarking on prolonged intensive medical therapy in an ill patient. Unfortunately the patient was shocked following her hepatic angiography and over the subsequent $48 \mathrm{hr}$ she became more jaundiced, the serum bilirubin level rising to $450 \mathrm{mmol} / \mathrm{l}$. In addition, 4 days after the procedure, the serum alanine aminotransferase level rose transiently to气 75 i.u. There was no evidence of further haemolysis to account for these changes. At that time, it was considered that her symptons could be the result of $a^{C} \cdot$ bacteraemia but no organism was isolated and no clinical improvement occurred following antibiotico treatment. Her condition had been improving untile the time of the hepatic angiography but from thate time, her condition rapidly deteriorated. Whether $\widehat{\varnothing}$ this was the result of a single complication of angiography overwhelming a compromised liver, or a $a^{\infty}$ combination of the hazards is impossible to say. $\overrightarrow{0}$ Complications of diagnostic arteriography are $\overrightarrow{-}$ considered to be uncommon but perhaps the use of hepatic angiography in the ill patient should be re=-0 considered in the light of this experience.

\section{Acknowledgments}

S.H. Davies for permission to reporto this case.

\section{References}

Alfidi, R.J., Rastogi, H., Buonocore, E. \& Brown, C.H.그 (1968) Hepatic angiography. Radiology, 90, 1136.

Bierman, H.R., Byron Jr, R.L., Kelley, K.H. \& Grady, A.ర (1951). Studies on the blood supply of tumours in man. III. Vascular patterns of the liver by hepatic arteriography in $\mathbb{\mathscr { Q }}$ vivo. Journal of the National Cancer Institute, 12, $107 \overline{3}$

Goldstein, H.M. \& Bookstein, J.J. (1974) Biochemicald evaluation of liver and pancreas following selective a\&d sub-selective angiography. Radiology, 111, 293.

RitchIE, W.G.M. (1975) The effect of contrast media onn normal and inflamed canine venous endothelium. (PB ceedings of the British Institute of Radiology.) British Joütnal of Radiology, 48, 945.

ZIEVE, L. (1958) Jaundice, hyperlipemia and hemolytic anemia: A heretofore unrecognized syndrome associated with alcoholic fatty liver and cirrhosis. Annals of Internal Medicine, 48, 471. 